\title{
Thrombin-linked aptamer assay for detection of platelet derived growth factor BB on magnetic beads in a sandwich format
}

\author{
Limin Guo ${ }^{\mathrm{a}, \mathrm{c}}$, Qiang Zhao ${ }^{\mathrm{a}, \mathrm{b}, *}$ \\ a Institute of Environmental Science, College of Chemistry and Chemical Engineering, Shanxi University, Taiyuan 030006, China \\ ${ }^{\mathrm{b}}$ State Key Laboratory of Environmental Chemistry and Ecotoxicology, Research Center for Eco-Environmental Sciences, Chinese Academy of Sciences, Beijing \\ 100085, China \\ ' School of Chinese Materia Medica, Shanxi University of Traditional Chinese Medicine, Taiyuan 030024, China
}

\section{A R T I C L E I N F O}

\section{Article history:}

Received 22 March 2016

Received in revised form

10 May 2016

Accepted 13 May 2016

Available online 14 May 2016

\section{Keywords:}

Aptamer

Thrombin

Enzyme label

Protein detection

Affinity binding

Platelet derived growth factor BB

\begin{abstract}
A B S T R A C T
Here we describe a thrombin-linked aptamer assay (TLAA) for protein by using thrombin as an enzyme label, harnessing enzyme activity of thrombin and aptamer affinity binding. TLAA converts detection of specific target proteins to the detection of thrombin by using a DNA sequence that consists of two aptamers with the first aptamer binding to the specific target protein and the second aptamer binding to thrombin. Through the affinity binding, the thrombin enzyme is labeled on the protein target, and thrombin catalyzes the hydrolysis of small peptide substrate into product, generating signals for quantification. As a proof of principle, we show a sandwich TLAA for platelet derived growth factor BB (PDGF$\mathrm{BB})$ by using anti-PDGF-BB antibody coated on magnetic beads and an oligonucleotide containing the aptamer for PDGF-BB and the aptamer for thrombin. The binding of PDGF-BB to both the antibody and the aptamer results in labeling the complex with thrombin. We achieved detection of PDGF-BB at 16 pM. This TLAA contributes a new application of thrombin and its aptamer in bioanalysis, and shows potentials in assay developments.
\end{abstract}

(c) 2016 Elsevier B.V. All rights reserved.

\section{Introduction}

Nucleic acid aptamers possess several desirable analytical features (e.g., small size, good stability, amplifiable property, switchable structures, ease of synthesis with low cost, and facile labeling with functional groups) [1-3], and have been involved in many applications [3-10]. Using aptamers as binding ligands, numerous assays have been developed for thrombin, an important enzyme molecule in blood with multiple functions. One recent review paper has summarized versatile formats of aptamer-based assays for thrombin detection [11]. Among these assays for thrombin [11], two DNA aptamers binding to thrombin are widely used, one 15-nt DNA aptamer (5'-GGT TGG TGT GGT TGG-3') [12] and one 29-nt DNA aptamer (5'-AGT CCG TGG TAG GGC AGG TTG GGG TGA CT-3') [13]. The 29-nt aptamer shows a much higher binding affinity (dissociation constant $\left(K_{\mathrm{d}}\right)$ around $0.5 \mathrm{nM}$ ) than the 15-nt aptamer $\left(K_{\mathrm{d}} \sim 100 \mathrm{nM}\right)$ [13]. Though many assay strategies for thrombin have been developed by using aptamers [3$5,11,14,15]$, the advances of sensitive detection of thrombin with

\footnotetext{
* Corresponding author at: Institute of Environmental Science, College of Chemistry and Chemical Engineering, Shanxi University, Taiyuan 030006, China.

E-mail addresses: qiangzhao@rcees.ac.cn, chemzhaoq@hotmail.com (Q. Zhao).

aptamer have not well benefited the detection of other proteins.

It is possible to apply thrombin aptamers to assays for nonthrombin targets. Previous research has made use of binding affinity of aptamer, binding-induced allosteric structure change, or enzyme activity of thrombin [3,5,10,16-18]. Yoshida et al. reported an aptameric enzyme subunit biosensing strategy for target detection in homogeneous solution $[17,18]$, which relied on the recovery or inhibition of clotting activity of thrombin caused by target-binding. Thrombin was also used as a signal enhancer in a fluorescence anisotropy aptamer assay for small molecules. This was achieved through a binding-induced mass change of a dyelabeled DNA probe [19].

Although aptamer binding can inhibit the clotting activity of thrombin in cleaving fibrinogen [12,13], the aptamer binding does not inactivate amidolytic activity of thrombin to cleave small peptide substrate. This is important: the aptamer-binding site on thrombin differs from the active site of thrombin enzyme activity $[12,13,20-25]$. Therefore, several highly sensitive assays for thrombin have used aptamer binding to one site and the thrombin enzyme activity on the other site. For example, thrombin could be captured on a solid support, and captured thrombin could subsequently catalyze the hydrolysis of small peptide substrates [2631]. We have achieved sensitive detection of thrombin by taking 
advantage of affinity preconcentration of thrombin onto aptamercoated magnetic beads [29-31]. These assays on the basis of aptamer capture only focused on the detection of thrombin.

Enzyme-linked assays (e.g., enzyme-linked immunosorbent assays (ELISA)) greatly improve assay sensitivity with an enzyme label to report binding events [32]. The use of aptamers as alternatives to antibodies allows the development of enzyme-linked aptamer assays [33-37]. In many enzyme linked aptamer assays, enzyme molecules (e.g., horseradish peroxidase and alkaline phosphatase) were usually attached on the aptamer or antibodies through antibody-antigen interaction, biotin-streptavidin (avidin) interaction, or chemical cross linking [33-37]. Rolling circle amplification (RCA) was also combined with the enzyme linked aptamer assay to further improve sensitivity [38]. Multiple streptavidin-labeled alkaline phosphatase molecules were attached on the RCA-generated oligos through the biotin-labeled complementary DNA sequences that hybridized with the RCA product [38]. In addition, DNAzyme was used as label in aptamer-based assays taking advantage of the activity of DNAzyme and direct coupling of DNAzyme sequences and aptamer sequences [3,39]. Lu's group developed a novel strategy to convert the target detection into the quantification of glucose by using a functional DNA-invertase conjugate as a label [40-42]. The invertase catalyzed the hydrolysis of sucrose into glucose, which was quantified by a simple glucose meter.

Herein, we described a thrombin-linked aptamer assay (TLAA) for protein detection by using thrombin as an enzyme label, converting specific protein target detection into thrombin analysis and showing new analytical applications of thrombin and its aptamers. Through rational design of an oligonucleotide probe contained a target-binding aptamer sequence and a thrombin-binding aptamer sequence, we readily labeled the thrombin enzyme onto the target. Scheme 1 shows the principle of TLAA for protein detection in a sandwich assay format using magnetic beads. The target of interest is first captured by antibody-coated magnetic beads. The antibody-bound target molecule on the magnetic beads then forms a sandwich complex with the first aptamer sequence of the oligonucleotide probe. The second aptamer sequence (for thrombin) of the oligonucleotide probe then binds to thrombin. Therefore, the target molecule is labeled with thrombin through the affinity binding events. Subsequently, thrombin catalyzes hydrolysis of a small peptide substrate into detectable product. To demonstrate the proof of principle of TLAA, here we showed an assay for platelet derived growth factor BB (PDGF-BB), an important protein regulating cell growth and division and a biomarker for many diseases [43-45]. We achieved detection of PDGF-BB at 16 pM in this sandwich TLAA on magnetic beads, and PDGF-BB spiked in diluted serum sample could be detected with TLAA. This TLAA has potential for detection of a wide range of other targets and for application in different assay formats.

\section{Materials and methods}

\subsection{Chemical and reagents}

Recombinant human PDGF-BB, PDGF-AB and PDGF-AA were obtained from Invitrogen. Bovine serum albumin (BSA), human immunoglobulin G (IgG), hemoglobin $(\mathrm{Hb})$, and lysozyme were purchased from Sigma. Anti-human PDGF-BB antibody coated magnetic beads were obtained from R\&D Systems (Cat. LANM 220). Human $\alpha$-thrombin was bought from Haematologic Technologies Inc. The fluorogenic substrate of thrombin, N-p-tosyl-GlyPro-Arg-7-amido-4-methylcoumarin hydrochloride and the chromogenic substrate of thrombin, N-p-tosyl-Gly-Pro-Arg-p-nitroanilide acetate, were purchased from Sigma. Oligonucleotide

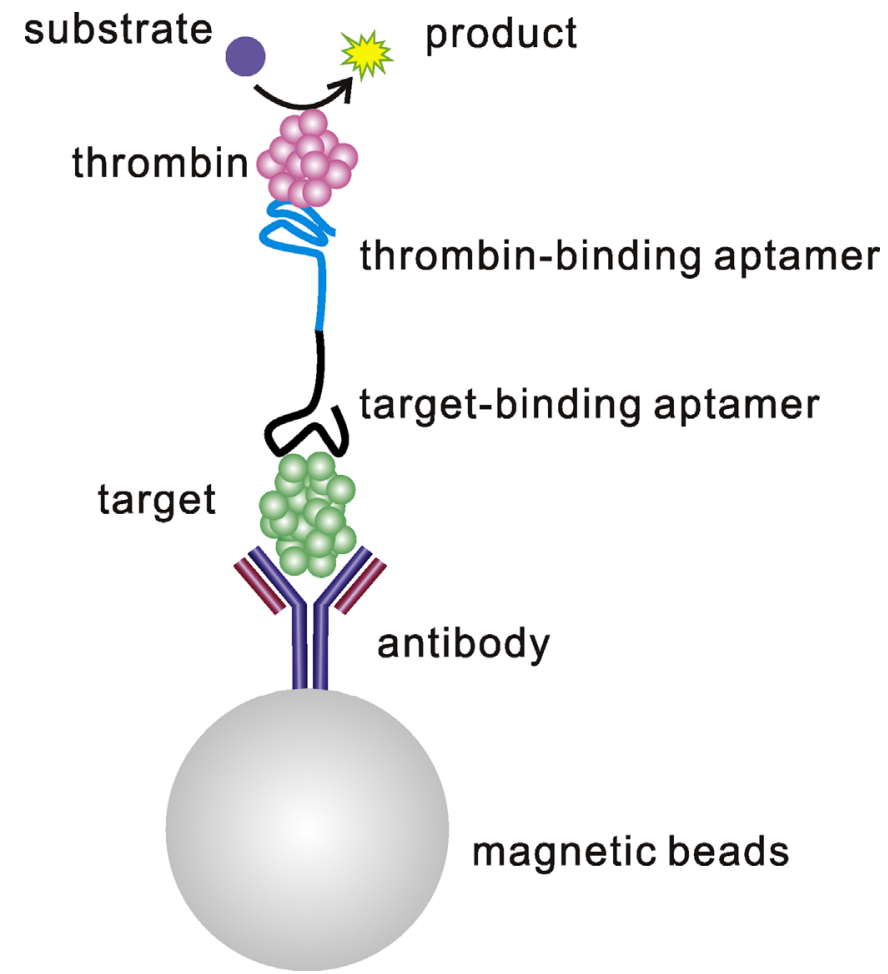

Scheme 1. Schematic diagram shows thrombin-linked aptamer assay (TLAA) for protein detection in a sandwich format on magnetic beads. The target protein is sandwiched by an antibody coated on magnetic beads and an affinity DNA probe containing target-binding aptamer sequence and thrombin-binding aptamer sequence. Thrombin is labeled to the sandwich complex through specific aptamerthrombin binding. Thrombin catalyzes the hydrolysis of a fluorogenic or chromogenic peptide substrate into a detectable product.

probes were synthesized and purified by Sangon Biotech (Shanghai, China). The sequence information of oligonucleotide probes was shown in Table S1 in Supplementary Material. Other reagents were all of analytical grade. The following buffers were used. Assay buffer contained $1 \times \mathrm{PBS}(137 \mathrm{mM} \mathrm{NaCl}, 2.7 \mathrm{mM} \mathrm{KCl}, 10 \mathrm{mM}$ $\mathrm{Na}_{2} \mathrm{HPO}_{4}, 2 \mathrm{mM} \mathrm{KH} \mathrm{PO}_{4}$, pH 7.5), $1 \mathrm{mM} \mathrm{MgCl}$ and $4 \mathrm{mg} / \mathrm{mL}$ BSA. Washing buffer contained $1 \times \mathrm{PBS}(\mathrm{pH} 7.5), 1 \mathrm{mM} \mathrm{MgCl}_{2}$ and $0.1 \%$ Tween 20. Enzyme reaction buffer contained $50 \mathrm{mM}$ Tris- $\mathrm{HCl}(\mathrm{pH}$ 8.5 ) and $1 \mathrm{M} \mathrm{NaCl}$. Ultrapure water was obtained from a Purelab Ultra Elga Labwater system and used in all runs.

\subsection{Procedure of PDGF-BB detection}

The ordered stock suspension solution of antibody coated magnetic beads was 100 -fold diluted with the assay buffer. $40 \mu \mathrm{L}$ of the dilution of the antibody coated beads was mixed with $100 \mu \mathrm{L}$ of PDGF-BB at different concentrations in the assay buffer, and the mixture was incubated at room temperature for $30 \mathrm{~min}$ The beads were separated from the unreacted reagent by the magnetic separator and washed with $50 \mu \mathrm{L}$ of washing buffer three times. Then, the beads were redispersed in $50 \mu \mathrm{L}$ of assay buffer containing oligonucleotide probes ( $50 \mathrm{nM}$ ), and incubated for $30 \mathrm{~min}$ The beads were separated and rinsed three times with $50 \mu \mathrm{L}$ of washing buffer. Next, $50 \mu \mathrm{L}$ of thrombin $(10 \mathrm{nM})$ in the assay buffer was added and incubated with magnetic beads for 30 min After magnetic separation, the beads were washed with $50 \mu \mathrm{L}$ of washing buffer three times. The magnetic beads were redispersed in $40 \mu \mathrm{L}$ of enzyme reaction buffer containing the fluorogenic substrate of thrombin $(0.12 \mathrm{mM})$, and the mixture was incubated at $37{ }^{\circ} \mathrm{C}$ for $2 \mathrm{~h}$. After magnetic separation, the solution was transferred into a new tube containing $80 \mu \mathrm{L}$ of $\mathrm{H}_{2} \mathrm{O} .100 \mu \mathrm{L}$ of the collected solution was added into wells of a 96-well 
microplate. The fluorescence was measured at $440 \mathrm{~nm}$ with an excitation of $370 \mathrm{~nm}$ by a microplate reader (Varioskan Flash, Thermo Fisher Scientific, Inc).

For an absorbance assay, the chromogenic substrate of thrombin was used instead of fluorogenic substrate in TLAA procedure. The chromogenic substrate of thrombin, N-p-tosyl-Gly-Pro-Arg-pnitroanilide $(0.5 \mathrm{mM})$, was applied in $50 \mu \mathrm{L}$ of enzyme reaction buffer solution. The thrombin catalyzed the cleavage of the chromogenic substrate to produce p-nitroaniline. After $2 \mathrm{~h}$-enzyme reaction at $37{ }^{\circ} \mathrm{C}$ and magnetic separation, the solution was transferred into a new tube containing $50 \mu \mathrm{L}$ of $\mathrm{H}_{2} \mathrm{O}$. The absorbance at $405 \mathrm{~nm}$ of the collected solution was recorded by UV-vis spectrometer (HITACHI U3010).

\section{Results and discussion}

\subsection{Assay feasibility and optimization of experimental conditions}

To demonstrate the proof of concept of TLAA (Scheme 1), we described an assay for detection of PDGF-BB as an example. AntiPDGF-BB antibody coated magnetic beads were used to capture PDGF-BB. The oligonucleotide, 5'-TAC TCA GGG CAC TGC AAG CAA TTG TGG TCC CAA TGG GCT GAG TA TTTTTT AGT CCG TGG TAG GGC AGG TTG GGG TGA CT-3' (denoted as PD44-6T-TH29), was used as an affinity probe. The boldface portion was the sequence of 44-nt aptamer (PD44) binding to PDGF-BB $\left(K_{\mathrm{d}} \sim 0.1 \mathrm{nM}\right)$ [46], and the underlined portion was the sequence of the 29-nt aptamer (TH29) binding to thrombin with high binding affinity $\left(K_{\mathrm{d}} \sim 0.5 \mathrm{nM}\right)$ [11]. Between the two aptamer portions was a poly-T linker (six $\mathrm{T}$ bases). Trace concentrations of PDGF-BB was captured on the antibody-coated magnetic beads. The antibody-bound PDGF-BB then formed a sandwich complex with the aptamer sequence of the PD44-6T-TH29 oligonucleotide probe. The other end of the PD446T-TH29 oligonucleotide probe further bound to thrombin. Therefore, the affinity interactions resulted in the labeling of the thrombin enzyme to the affinity complex of the target PDGF-BB protein. As an enzyme, thrombin catalyzed the cleavage of a fluorogenic peptide substrate (N-p-tosyl-Gly-Pro-Arg-7-amido-4methylcoumarin) at the Arg site, to generate a fluorescent product, 7-amino-4-methylcoumarin, which emitted fluorescence at $440 \mathrm{~nm}$ with an excitation at $370 \mathrm{~nm}$ [47]. The fluorescence measurement of the generated product afforded quantitative information for the determination of PDGF-BB.

We first tested the feasibility of TLAA for PDGF-BB. As Fig. 1 (A) shows, the presence of PDGF-BB caused a large fluorescence signal (fluorescence intensity was shown with RFU, relative fluorescence units), much higher than that from the blank sample that did not contain PDGF-BB. This result suggests that the principle of TLAA is feasible for PDGF-BB detection.

We then optimized the pertinent assay conditions, including the concentration of $\mathrm{Mg}^{2+}$ in the assay buffer, the concentration of oligonucleotide probe, the concentration of thrombin, and the length of linker between the PDGF-BB aptamer sequence and the thrombin aptamer sequence. In each set of experiments, we included a sample of 1 nM PDGF-BB and a blank that contained all the reagents but no PDGF-BB. We then subtracted fluorescence intensity of the blank from the fluorescence signal of the PDGF-BB sample, giving net increase in fluorescence intensity ( $\Delta \mathrm{RFU})$.

We tested how the concentration of $\mathrm{Mg}^{2+}$ in the assay buffer affected $\Delta$ RFU (Fig. $1(B)$ ). These results show that an optimum concentration of $\mathrm{Mg}^{2+}$ ion $(1 \mathrm{mM})$ is necessary for the PDGF-BB binding assay. This finding is consistent with previous report that divalent ions may stabilize the three-way helix structure of the PDGF-BB aptamer $[46,48]$. Too high a concentration of metal ion may weaken the affinity of aptamer with protein [48]. Therefore,
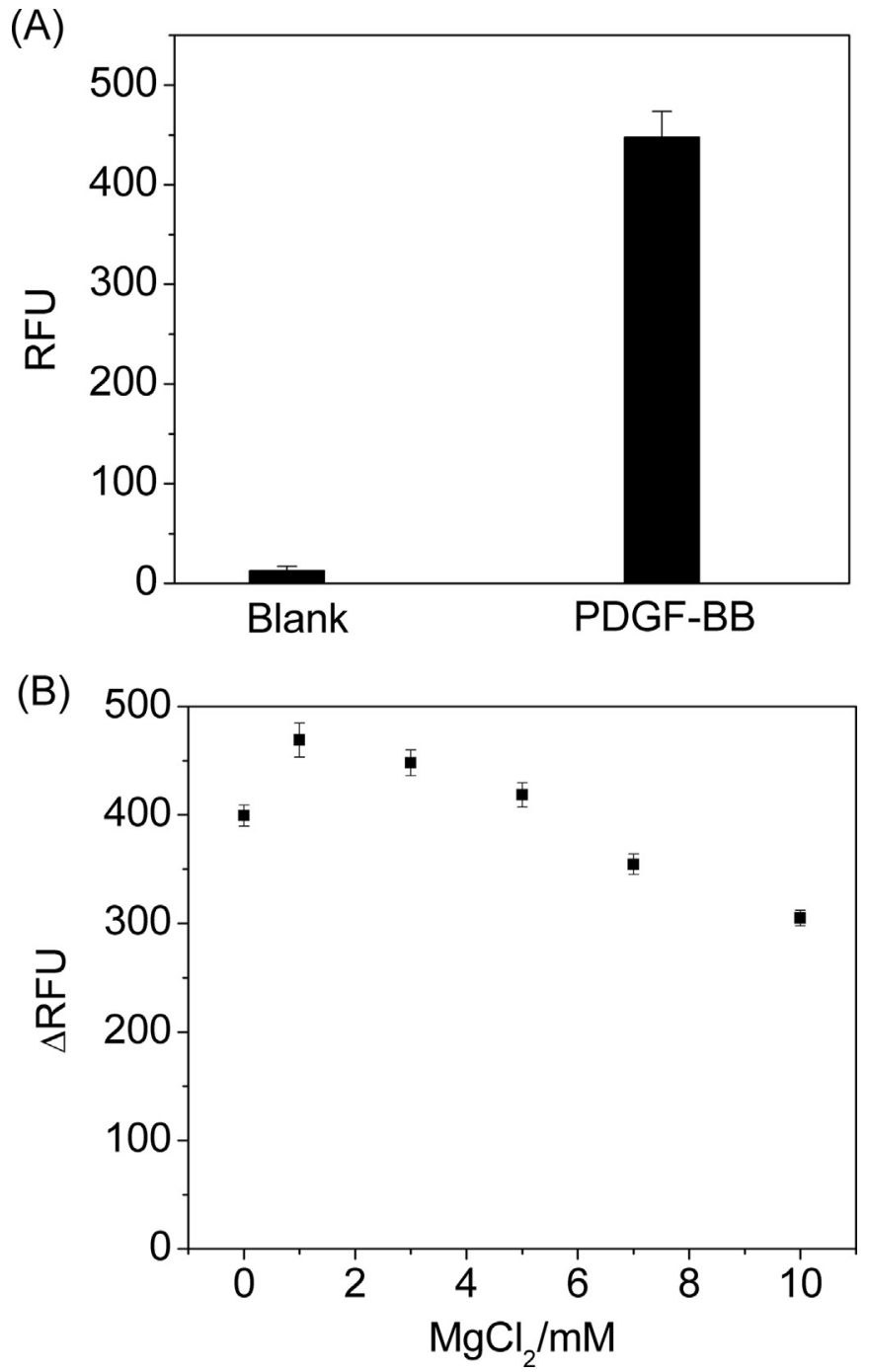

Fig. 1. (A) Testing the feasibility of TLAA for PDGF-BB by using PD44-6T-TH29 probe. Blank sample and $1 \mathrm{nM}$ PDGF-BB were analyzed. Fluorescence intensity was expressed as relative fluorescence units (RFU). (B) Effect of the $\mathrm{Mg}^{2+}$ concentration in the assay buffer on the net increase in fluorescence intensity $(\triangle \mathrm{RFU})$. The concentration of PDGF-BB was $1 \mathrm{nM}$. Aptamer at $50 \mathrm{nM}$ and thrombin at $10 \mathrm{nM}$ were used.

$\mathrm{MgCl}_{2}$ at $1 \mathrm{mM}$ was chosen in the present study.

The concentration of the used oligonucleotide probe influenced TLAA for PDGF-BB (Fig. 2(A)). The use of $50 \mathrm{nM}$ oligonucleotide probe allowed for the highest $\triangle \mathrm{RFU}$, so this concentration was chosen in the TLAA for PDGF-BB. Fig. 2(B) shows the effect of the concentration of thrombin on the assay performance. $\triangle \mathrm{RFU}$ increased with the increase of thrombin concentration from $2.5 \mathrm{nM}$ to $10 \mathrm{nM}$, and $\Delta \mathrm{RFU}$ reached a maximum value when $10 \mathrm{nM}$ of thrombin was used. Further increase in the concentration of thrombin to $40 \mathrm{nM}$ caused slight decrease in the $\Delta \mathrm{RFU}$ value. Thus, thrombin at $10 \mathrm{nM}$ was used in this assay.

We investigated the influence of the length of the poly-T linker between the two aptamer sequences in the oligonucleotide probe (Fig. 3). Table S1 in Supplementary Material shows the list of the tested oligonucleotide probes with different length of the poly-T linkers. The length of linkers of repeated $\mathrm{T}$ bases ranged from $0 \mathrm{~T}$ to $18 \mathrm{~T}$ 's. Too long of a poly-T linker caused decreases in $\Delta$ RFU. A short linker with 3 T's (PD44-3T-TH29) also decreased $\Delta$ RFU. The oligonucleotide probe without using linkers (PD44-0T-TH29) did not seem to affect $\Delta$ RFU. The reason for these differences are not clear. The linkers with 6 T's (PD44-6T-TH29) consistently resulted 

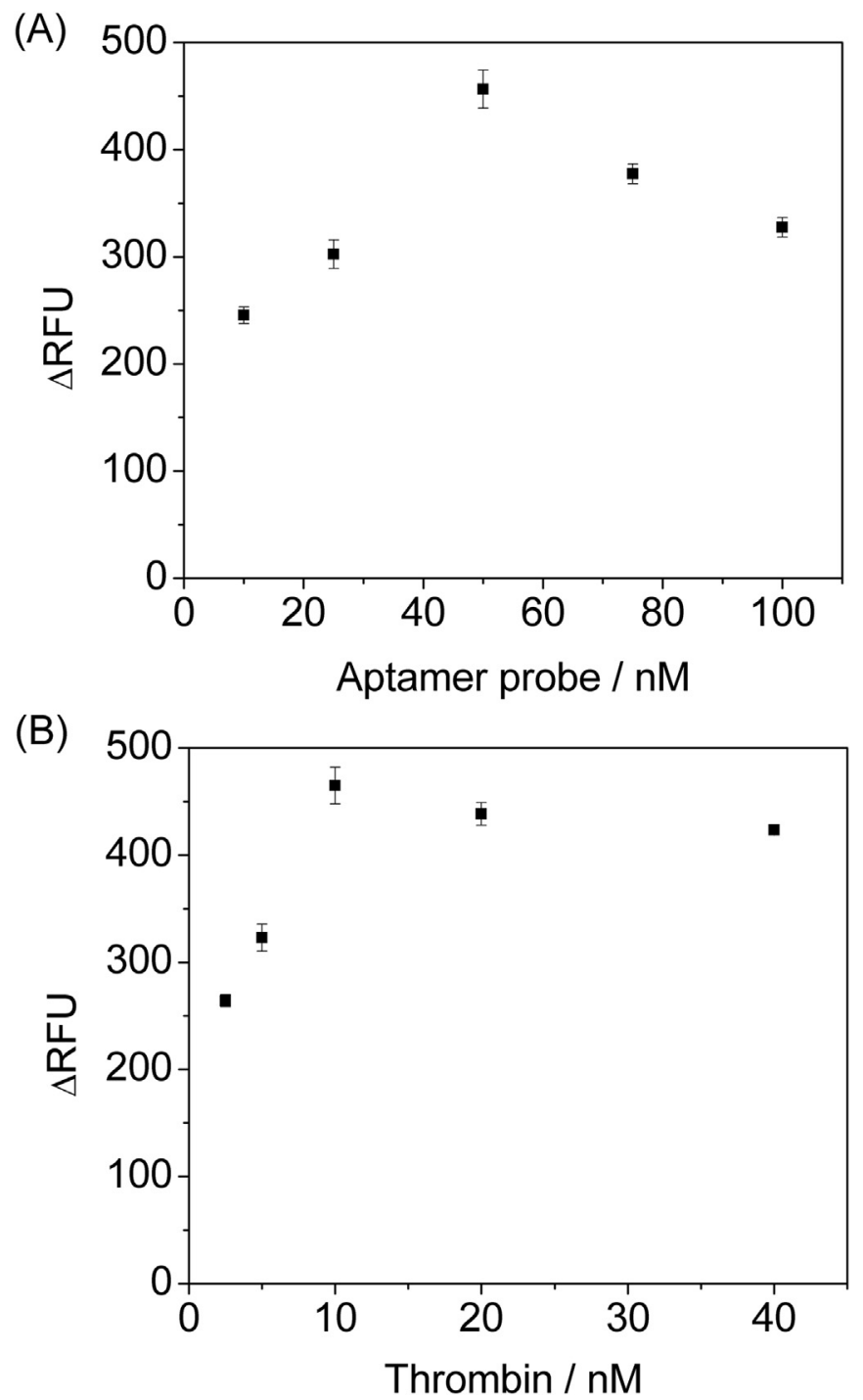

Fig. 2. (A) Effect of the concentration of DNA probe (PD44-6T-TH29) on the net increase in fluorescence intensity $(\triangle R F U)$. (B) The effect of concentration of applied thrombin on $\triangle \mathrm{RFU}$.

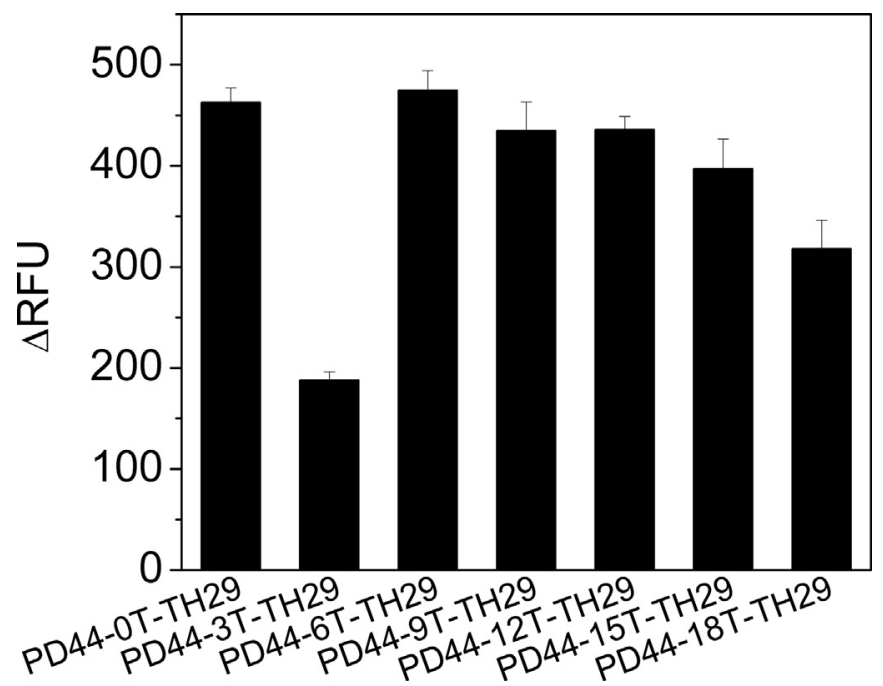

Fig. 3. Influence of the linker length of the oligonucleotide probe on the net increase in fluorescence intensity $(\triangle \mathrm{RFU})$. The oligonucleotide probes were composed of a 44-nt aptamer sequence (PD44) for PDGF-BB, a 29-nt aptamer sequence (TH29) for thrombin, and a poly-T linker of variable lengths (from $0 \mathrm{~T}$ to $18 \mathrm{~T}$ ).
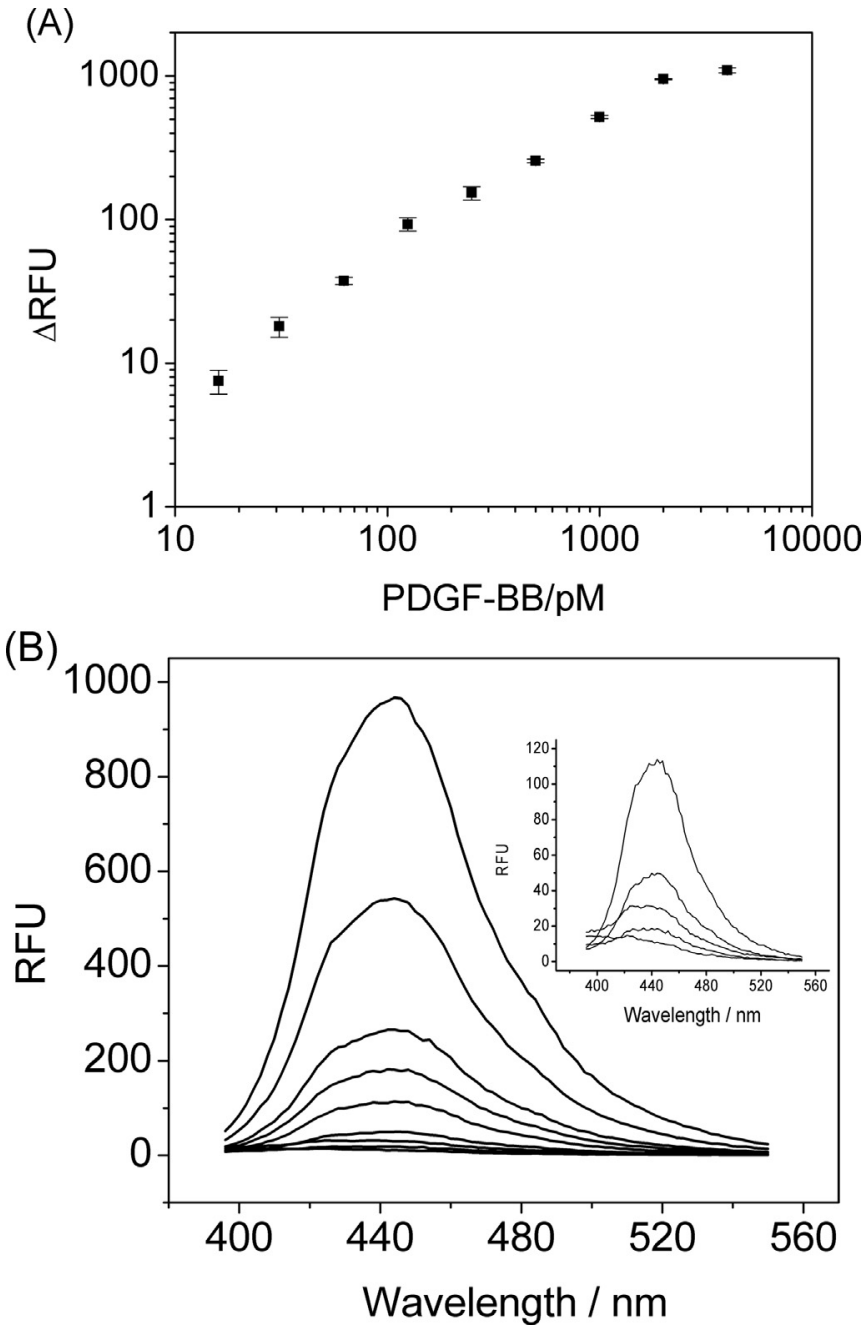

Fig. 4. Detection of varying concentrations of PDGF-BB by TLAA using fluorogenic substrate. (A) Plot shows $\triangle$ RFU versus PDGF-BB concentration. Logarithmic scale was used here. (B) The recorded fluorescence spectra of the generated fluorescent product, corresponding to concentrations of PDGF-BB ranging from 0 to $2 \mathrm{nM}$. The inset shows the obtained fluorescence spectra corresponding to PDGF-BB at concentrations 0,16 pM, $32 \mathrm{pM}, 63 \mathrm{pM}$, and $125 \mathrm{pM}$ (from the bottom curve to the top curve).

in optimum $\Delta$ RFU for the detection of PDGF-BB. Therefore, we chose to use the oligonucleotide probe (PD44-6T-TH29) consisting of the 6T linker to connect the two aptamer sequences.

\subsection{Performance of assays}

Under the optimized experiment conditions, we successfully detected varying concentrations of PDGF-BB with our TLAA (Fig. 4). A linear relationship was obtained between $\triangle \mathrm{RFU}$ and the concentration of PDGF-BB ranging from $16 \mathrm{pM}$ to $2 \mathrm{nM}(\mathrm{y}=0.487 \mathrm{x}$, $R^{2}=0.995$ ). The limit of detection (LOD) on the basis of 3 times the standard deviation of the blank was $16 \mathrm{pM}$. This detection limit is comparable to or better than those reported by some aptamerbased assays for PDGF-BB [3,5,8,9,48-55]. An aptamer proximity binding assay for fluorescent detection of PDGF-BB was reported, which did not require separation [53]. The binding of two aptamers to PDGF-BB led to formation of a G-quadruplex that can bind to fluorescent dye to generate enhanced fluorescent signals. This assay allowed for detection of 3.2 nM PDGF-BB [53], and it showed a lower sensitivity than our assay. The sensitivity of TLAA was lower than that obtained from the PCR based assay [56], RCA electrochemical assay that combined multiple signal amplification 


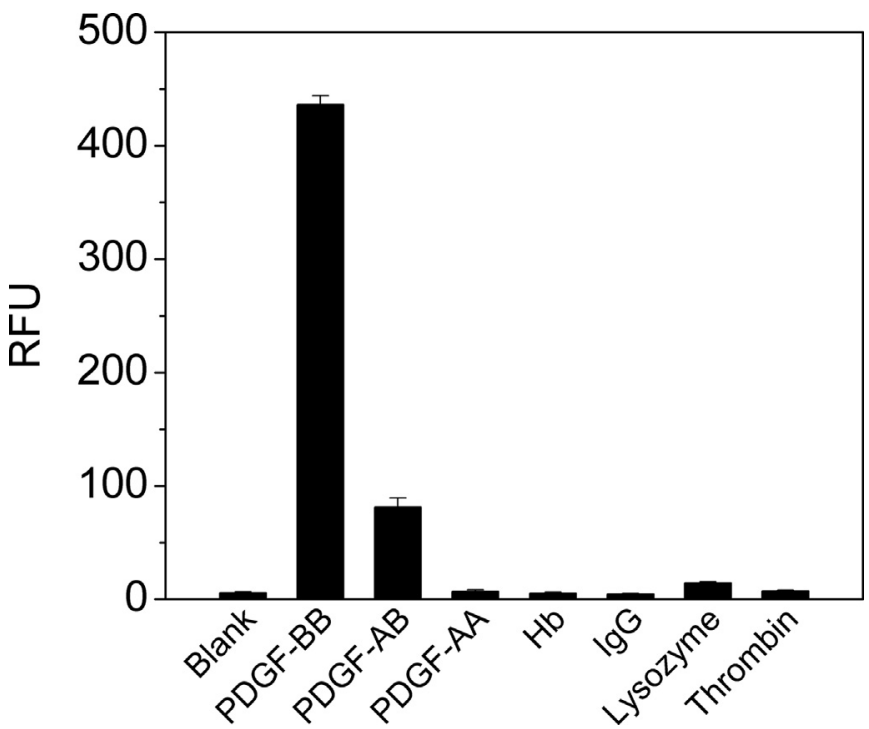

Fig. 5. Selectivity test of TLAA for PDGF-BB. The tested proteins included PDGF-BB (1 nM), PDGF-AB (1 nM), PDGF-AA (1 nM), hemoglobin (Hb, $16 \mu \mathrm{M})$, IgG $(7 \mu \mathrm{M})$, lysozyme $(57 \mu \mathrm{M})$, and thrombin $(20 \mathrm{nM})$.

processes (enzyme amplification, RCA, and electrochemical amplification) [38], or RCA assays coupled with DNAzyme amplification [39]. Table S2 in Supplementary Material shows a comparison of a few aptamer based assays for PDGF-BB with respect to detection limit.

When chromogenic substrate was used, simple and commonly used absorbance analysis could be applied to detect PDGF-BB using TLAA. Thrombin catalyzed the cleavage of the chromogenic substrate of N-p-tosyl-Gly-Pro-Arg-p-nitroanilide into a colored product of nitroaniline. In this case, we could detect PDGF-BB ranging from $0.25 \mathrm{nM}$ to $8 \mathrm{nM}$ by measuring the net increase of absorbance at $405 \mathrm{~nm}$ (shown in Fig. S1 in Supplementary Material)). The use of chromogenic substrate in TLAA also makes colorimetric assay feasible as the generated product is colored, and target detection can be achieved by observing the color change of the solution without using instruments, which will be useful for point-of-care applications. Because the generated product can be measured with electrochemical method [26,27], it is also possible to apply electrochemical detection method for TLAA. Though a sandwich format TLAA is demonstrated here for PDGF-BB, other assay formats of TLAA (e.g., competitive format) can be expected.

The use of thrombin as enzyme label here does not require complicated and time-consuming chemical conjugation of enzyme molecules to affinity ligands (e.g. antibodies, aptamers, streptavidin, and etc). The used oligonucleotide in TLAA can be directly synthesized to contain two aptamer sequences with low cost. The use of thrombin as a label in the assay has a few advantages, such as the small size of thrombin-binding aptamer with short sequence, the selective and high binding affinity of the aptamer, ease of obtaining thrombin, high amidolytic activity of thrombin toward small peptide substrate, and available substrates for different detection formats.

\subsection{Selectivity test}

We assessed the specificity of the present TLAA for PDGF-BB by testing other proteins, including hemoglobin ( $\mathrm{Hb})$, immunoglobulin $\mathrm{G}(\operatorname{IgG})$, and lysozyme at concentrations 1000 times higher than PDGF-BB. These tested proteins did not cause interference with the detection of PDGF-BB (shown in Fig. 5). The presence of thrombin ( $20 \mathrm{nM}$ ) did not interfere with the detection of PDGF-BB as the antibody for PDGF-BB did not bind with thrombin. Two other isomers of PDGF, PDGF-AA and PDGF-AB, were analyzed. PDGF-AA caused a negligible signal. In the case of PDGF-AB, the obtained signal was about $22 \%$ of that for PDGF-BB. The main reason is that the selected aptamer binds to PDGF $B$ chain with much higher affinity than PDGF A chain [46,52]. PDGF$A B$ consists of $A$ and $B$ chains, and the $B$ chain can bind with the aptamer, and the combination of aptamer and antibody can distinguish the difference between PDGF-AB and PDGF-BB. The result is consistent with the previous report about the detection of PDGF-BB by using apamers [48,51-53].

We also tested the feasibility and applicability of the assay for target spiked in complex matrix. PDGF-BB spiked in 100-fold diluted human serum sample could be detected with our assay (Fig. S2 in Supplementary Material). The detection limit was $16 \mathrm{pM}$, which was the same as that obtained in the assay buffer. The measured $\triangle$ RFU shows a good linear relationship with the concentration of PDGF-BB in the range of $16-2000 \mathrm{pM}(\mathrm{y}=0.475 \mathrm{x}$, $\left.R^{2}=0.995\right)$. The average recovery of the PDGF-BB spiked in 100fold diluted human serum at $31 \mathrm{pM}, 62.5 \mathrm{pM}, 125 \mathrm{pM}$, and $250 \mathrm{pM}$ was $94 \%, 103 \%, 96 \%$ and $103 \%$, respectively. These results suggest that this assay can be used to detect PDGF-BB in a complex matrix after appropriate dilution of the sample. Further research is needed to increase the tolerance of interference and allow for direct analysis of complex samples without dilution.

\section{Conclusion}

In summary, sensitive detection of PDGF-BB through indirect detection of thrombin is achieved by using the thrombin-linked aptamer assay (TLAA) on magnetic beads. This assay benefits from the rational design of a bi-functional oligonucleotide probe that is composed of an aptamer sequence binding to the target protein and the second aptamer sequence binding to thrombin. The target-binding aptamer sequence and the thrombin-binding aptamer sequence facilitate the recognition of the target and the introduction of the thrombin label. Thus, detection of the target protein is converted into the detection of thrombin. As an enzyme, thrombin can catalyze the cleavage of fluorogenic or chromogenic peptide substrates to generate detectable products. Because of the signal amplification from thrombin catalysis reaction, the assay sensitivity is enhanced. This strategy has potential in bioanalysis and biosensing of other targets in a variety of assay formats by using thrombin as an enzyme label or reporter. This approach provides new applications of thrombin-binding aptamer in assay developments and biosensors.

\section{Acknowledgements}

This work was supported by National Natural Science Foundation of China (Grant No. 21222503, 21435008) and Outstanding Youth Talents Program of Shanxi Province.

\section{Appendix A. Supplementary material}

Supplementary data associated with this article can be found in the online version at http://dx.doi.org/10.1016/j.talanta.2016.05. 037.

\section{References}


specific ligands, Nature 346 (1990) 818-822.

[2] C. Tuerk, L. Gold, Systematic evolution of ligands by exponential enrichment: RNA ligands to bacteriophage T4 DNA polymerase, Science 249 (1990) 505-510.

[3] F. Li, H. Zhang, Z. Wang, A.M. Newbigging, M.S. Reid, X.F. Li, X.C. Le, Aptamers facilitating amplified detection of biomolecules, Anal. Chem. 87 (2015) 274-292.

[4] E.J. Cho, J.W. Lee, A.D. Ellington, Applications of aptamers as sensors, Annu. Rev. Anal. Chem. 2 (2009) 241-264.

[5] J. Liu, Z. Cao, Y. Lu, Functional nucleic acid sensors, Chem. Rev. 109 (2009) 1948-1998.

[6] B. Deng, J. Chen, H. Zhang, Assembly of multiple DNA components through target binding toward homogeneous, isothermally amplified, and specific detection of proteins, Anal. Chem. 86 (2014) 7009-7016.

[7] A.B. Iliuk, H. Lianghai, T.W. Andy, Aptamer in bioanalytical applications, Anal. Chem. 83 (2011) 4440-4452.

[8] Y.S. Kim, N.H.A. Raston, M.B. Gu, Aptamer-based nanobiosensors, Biosens. Bioelectron. 76 (2016) 2-19.

[9] M. Yüce, N. Ullahb, H. Budak, Aptamers in analytics, Analyst 140 (2015) 5379-5399.

[10] W. Yoshida, K. Abe, K. Ikebukuro, Emerging techniques employed in aptamerbased diagnostic tests, Expert Rev. Mol. Diagn. 14 (2014) 143-151.

[11] B. Deng, Y. Lin, C. Wang, F. Li, Z. Wang, H. Zhang, X.F. Li, X.C. Le, Aptamer binding assays for proteins: the thrombin example- A review, Anal. Chim. Acta 837 (2014) 1-15.

[12] L.C. Bock, L.C. Griffin, J.A. Latham, E.H. Vermaas, J.J. Toole, Selection of singlestranded-DNA molecules that bind and inhibit human thrombin nature, Nature 355 (1992) 564-566.

[13] D.M. Tasset, M.F. Kubik, W. Steiner, Oligonucleotide inhibitors of human thrombin that bind distinct epitopes, J. Mol. Biol. 272 (1997) 688-698.

[14] S. Pai, A. Roberts, A.D. Ellington, Aptamer amplification: divide and signal, Expert. Opin. Med. Diagn. 2 (2008) 1333-1346.

[15] H. Zhang, F. Li, B. Dever, X.F. Li, X.C. Le, DNA-mediated homogeneous binding assays for nucleic acids and proteins, Chem. Rev. 113 (2013) 2812-2841.

[16] V. Pavlov, B. Shlyahovsky, I. Willner, Fluorescence detection of DNA by the catalytic activation of an aptamer/thrombin complex, J. Am. Chem. Soc. 127 (2005) 6522-6523.

[17] W. Yoshida, K. Abe, K. Ikebukuro, Aptameric enzyme subunit for biosensing based on enzymatic activity measurement, Anal. Chem. 78 (2006) 3296-3303.

[18] W. Yoshida, K. Abe, K. Ikebukuro, Label-free homogeneous detection of immunoglobulin E by an aptameric enzyme subunit, Biotechnol. Lett. 30 (2008) 421-425.

[19] L. Cui, Y. Zou, N.H. Lin, Z. Zhu, G. Jenkins, C.J. Yang, Mass amplifying probe for sensitive fluorescence anisotropy detection of small molecules in complex biological samples, Anal. Chem. 84 (2012) 5535-5541.

[20] A.B. Dobrovolsky, E.V. Titaeva, S.G. Khaspekova, V.A. Spiridonova, A. M. Kopylov, A.V. Mazurov, Inhibition of thrombin activity with DNA-aptamers, Bull. Exp. Biol. Med. 148 (2009) 33-36.

[21] J. Liu, P. Schuff-Werner, M. Steiner, Aptamer and inhibition of thrombin clotting activity: a note of caution, Thromb. Res. 107 (2002) 281-282.

[22] A.V. Mazurov, E.V. Titaeva, S.G. Khaspekova, A.N. Storojilova, V.A. Spiridonova, A.M. Kopylov, A.B. Dobrovolsky, Characteristics of a new DNA aptamer, direct inhibitor of thrombin, Bull. Exp. Biol. Med. 150 (2011) 422-425.

[23] N.S. Petrera, A.R. Stafford, B.A. Leslie, C.A. Kretz, J.C. Fredenburgh, J.I. Weitz, Long range communication between exosites 1 and 2 modulates thrombin function, J. Biol. Chem. 284 (2009) 25620-25629.

[24] Q. Wu, M. Tsiang, J.E. Sadler, Localization of the single-stranded DNA binding site in the thrombin anion-binding exosite, J. Biol. Chem. 267 (1993) $24408-24412$.

[25] G. Zhou, X. Huang, Y. Qu, The binding effect of aptamers on thrombin, Biochem. Eng. J. 52 (2010) 117-122.

[26] S. Centi, G. Messina, S. Tombelli, I. Palchetti, M. Mascini, Different approaches for the detection of thrombin by an electrochemical aptamer-based assay coupled to magnetic beads, Biosens. Bioelectron. 23 (2008) 1602-1609.

[27] M. Mir, M. Vreeke, I. Katakis, Different strategies to develop an electrochemical thrombin aptasensor, Electrochem. Commun. 8 (2006) 505-511.

[28] J. Müller, T. Becher, J. Braunstein, P. Berdel, S. Gravius, F. Rohrbach, J. Oldenburg, G. Mayer, B. Potzsch, Profiling of active thrombin in human blood by supramolecular complexes, Angew. Chem. Int. Ed. 50 (2011) 6075-6078.

[29] Q. Zhao, X.-F. Li, X.C. Le, Aptamer capturing of enzymes on magnetic beads to enhance assay specificity and sensitivity, Anal. Chem. 83 (2011) 9234-9236.

[30] Q. Zhao, X.F. Wang, An aptamer-capture based chromogenic assay for thrombin, Biosens. Bioelectron. 34 (2012) 232-237.

[31] Q. Zhao, J. Gao, An affinity capture involved enzymatic assay for thrombin by using peptide aptamers as affinity ligands on magnetic beads, Chem. Commun. 49 (2013) 7720-7722.

[32] R.M. Lequin, Enzyme immunoassay (EIA)/ enzyme-linked immunosorbent assay (ELISA), Clin. Chem. 51 (2005) 2415-2418.

[33] E. Baldrich, J.L. Acero, G. Reekmans, W. Laureyn, C.K. OSullivan, Displacement enzyme linked aptamer assay, Anal. Chem. 77 (2005) 4774-4784.

[34] D.W. Drolet, L. Moon-McDermott, T.S. Romig, An enzyme-linked oligonucleotide assay, Nat. Biotechnol. 14 (1996) 1021-1025.

[35] A.K. Sharma, A.D. Kent, J.M. Heemstra, Enzyme-linked small-molecule detection using split aptamer ligation, Anal. Chem. 84 (2012) 6104-6109.

[36] J. Shimada, T. Maruyama, M. Kitaoka, N. Kamiya, M. Goto, Microplate assay for aptamer-based thrombin detection using a DNA-enzyme conjugate based on histidine-tag chemistry, Anal. Biochem. 421 (2012) 541-546.

[37] S.Y. Toh, M. Citartan, S.C.B. Gopinath, T.-H. Tang, Aptamers as a replacement for antibodies in enzyme-linked immunosorbent assay, Biosens. Bioelectron. 64 (2015) 392-403.

[38] L. Zhou, L.J. Ou, X. Chu, G.L. Shen, R.Q. Yu, Aptamer-based rolling circle amplification: a platform for electrochemical detection of protein, Anal. Chem. 79 (2007) 7492-7500.

[39] L.H. Tang, Y. Liu, M.M. Ali, D. Kang, W.A. Zhao, J.H. Li, Colorimetric and ultrasensitive bioassay based on a dual-amplification system using aptamer and DNAzyme, Anal. Chem. 84 (2012) 4711-4717.

[40] Y. Xiang, Y. Lu, Using personal glucose meters and functional DNA sensors to quantify a variety of analytical targets, Nat. Chem. 3 (2011) 697-703.

[41] Y. Xiang, Y. Lu, Using commercially available personal glucose meters for portable quantification of DNA, Anal. Chem. 84 (2012) 1975-1980.

[42] Y. Xiang, Y. Lu, Portable and quantitative detection of protein biomarkers and small molecular toxins using antibodies and ubiquitous personal glucose meters, Anal. Chem. 84 (2012) 4174-4178.

[43] A.A. Farooqi, S. Waseem, A.M. Riaz, B.A. Dilawar, S. Mukhtar, S. Minhaj, M. S. Waseem, S. Daniel, B.A. Malik, A. Nawaz, S. Bhatti, PDGF: the nuts and bolts of signalling toolbox, Tumor Biol. 32 (2011) 1057-1070.

[44] C.H. Heldin, Structural and functional studies on platelet-derived growth factor, EMBO J. 11 (1992) 4251-4259.

[45] J. Yu, C. Ustach, H.-R.C. Kim, Platelet-derived growth factor signaling and human cancer, J. Biochem. Mol. Biol. 36 (2003) 49-59.

[46] L.S. Green, D. Jellinek, R. Jenison, A. Ostman, C.H. Heldin, N. Janjic, Inhibitory DNA ligands to platelet-derived growth factor B-chain, Biochemistry 35 (1996) 14413-14424.

[47] R. Lottenberg, U. Christensen, C.M. Jackson, P.L. Coleman, Assay of coagulation proteases using peptide chromogenic and fluorogenic substrates, Methods Enzymol. 80 (1981) 341-361.

[48] X.H. Fang, Z.H. Cao, T. Beck, W.H. Tan, Molecular aptamer for real-time oncoprotein platelet-derived growth factor monitoring by fluorescence anisotropy, Anal. Chem. 73 (2001) 5752-5757.

[49] C.C. Huang, S.H. Chiu, Y.F. Huan, H.T. Chang, Aptamer-functionalized gold nanopaticles for turn-on light switch detection of platelet-derived growth factor Anal. Chem. 79 (2007) 4798-4804.

[50] L. Joonhyung, I. Kutay, R. Ana, A.D. Ellington, C.A. Savran, Diffractometric detection of proteins using microbead-based rolling circle amplification, Anal. Chem. 82 (2010) 197-202.

[51] C.J. Yang, S. Jockusch, M. Vicens, N.J. Turro, W.H. Tan, Light-switching excimer probes for rapid protein monitoring in complex biological fluids, Proc. Natl. Acad. Sci. USA 102 (2005) 17278-17283.

[52] H. Zhang, X.F. Li, X.C. Le, Differentiation and detection of PDGF isomers and their receptors by tunable aptamer capillary electrophoresis, Anal. Chem. 81 (2009) 7795-7800.

[53] Y. Wei, W. Zhou, J. Liu, Y. Chai, Y. Xiang, R. Yuan, Label-free and homogeneous aptamer proximity binding assay for fluorescent detection of protein biomarkers in human serum, Talanta 141 (2015) 230-234.

[54] P. Wang, Y. Song, Y. Zhao, A. Fan, Hydroxylamine amplified gold nanoparticlebased aptameric system for the highly selective and sensitive detection of platelet-derived growth factor, Talanta 103 (2013) 392-397.

[55] X. Wang, W. Li, Z. Li, H. Li, D. Xu, A highly sensitive fluorescence turn-on platform with silver nanoparticles aptasening for human platelet-derived growth factor-BB, Talanta 144 (2015) 1273-1278.

[56] A. Csordas, A.E. Gerdon, J.D. Adams, J. Qian, S.S. Oh, Y. Xiao, H.T. Soh, Detection of proteins in serum by micromagnetic aptamer PCR (MAP) technology, Angew. Chem. Int. Ed. 49 (2010) 355-358. 